\title{
How Are Primary Care Systems Engaging With Social Needs?
}

\author{
Irina M. Padua, MD, Michael E. Jobansen, MD, MS, Associate Editor \\ Ann Fam Med 2021;19(6):iii. https://doi.org/10.1370/afm.2750.
}

$\mathrm{T}$ The Annals of Family Medicine encourages readers to develop a learning community to improve health care and health through enhanced primary care. Participate by conducting a journal club. We encourage diverse participants to think critically about important issues affecting primary care and act on those discussions. ${ }^{1}$

\section{HOW IT WORKS}

In each issue, the Annals selects an article and provides discussion tips and questions. Post a summary of your conversation in our online discussion. (Open the article, click on the eLetters tab, and submit a comment.) Discussion questions and information are online at: https://www.AnnFamMed.org/content/AJC.

\section{CURRENT SELECTION}

Fraze TK, Beidler LB, Fichtenberg C, Brewster AL, Gottlieb LM. Resource brokering: efforts to assist patients with housing, transportation, and economic needs in primary care settings. Ann Fam Med. 2021:19(6):507-514.

\section{Discussion Tips}

Health outcomes are, in part, determined by social, economic, and behavioral factors. Primary care systems are responsible for whole person care, which leads systems to help patients with patients' social adversity. However, information regarding how primary care systems are addressing patients' social needs is sparse. Better information might help systems improve patient care and outcomes. This study used semistructured interviews with leaders and frontline staff at health care organizations that engage in social care in order to gain insight on how systems are approaching social needs of patients.

\section{Discussion Questions}

- What questions are asked by this study and why do they matter?

- How were organizations and interviewees selected?

- What are semistructured interviews?

- What is intercoder reliability? Why does this matter?

- How strong is the study design for answering the study question?

- What are the benefits and weaknesses of semistructured interviews?

- To what degree can the findings be accounted for by:

- How primary care settings were selected, excluded, or lost to follow-up?

$\circ$ The time frame of the study?

- How the main outcome variables were measured?

- How the qualitative interviews were analyzed?

- What are the main study findings?

- How comparable is the study sample to your primary care setting? What is your judgment about the transportability of the findings?

- How might primary care settings address some of the barriers to incorporating social care into practice?

-What contextual factors are important for interpreting the findings?

- How might this study change your practice? Education? Research?

-What are the next steps in interpreting or applying the finding?

- What researchable questions remain?

\section{References}

1. Stange KC, Miller WL, McLellan LA, et al. Annals Journal Club: it's time to get RADICAL. Ann Fam Med. 2006;4(3):196-197. https:// www.AnnFamMed.org/cgi/content/full/4/3/196. 